\title{
A Functional Role for Small-Conductance Calcium-Activated Potassium Channels in Sensory Pathways Including Nociceptive Processes
}

\author{
Parmvir K. Bahia, ${ }^{1}$ Rie Suzuki, ${ }^{1}$ David C. H. Benton, ${ }^{1}$ Amanda J. Jowett, ${ }^{2}$ Mao Xiang Chen, ${ }^{2}$ Derek. J. Trezise, ${ }^{2}$ \\ Anthony H. Dickenson, ${ }^{1}$ and Guy W. J. Moss ${ }^{1}$ \\ ${ }^{1}$ Department of Pharmacology, University College London, London WC1E 6BT, United Kingdom, and ${ }^{2}$ GlaxoSmithKline Research and Development, \\ Stevenage SG1 2NY, United Kingdom
}

\begin{abstract}
We investigated the role of small-conductance calcium-activated potassium (SK) and intermediate-conductance calcium-activated potassium channels in modulating sensory transmission from peripheral afferents into the rat spinal cord. Subunit-specific antibodies reveal high levels of SK3 immunoreactivity in laminas I, II, and III of the spinal cord. Among dorsal root ganglion neurons, both peripherin-positive (C-type) and peripherin-negative (A-type) cells show intense SK3 immunoreactivity. Furthermore, dorsal rootstimulated sensory responses recorded in vitro are inhibited when SK channel activity is increased with 1-ethyl-2-benzimidazolinone (1-EBIO). In vivo electrophysiological recordings show that neuronal responses to naturally evoked nociceptive and nonnociceptive stimuli increase after application of the selective SK channel blocker 8,14-diaza-1,7(1,4)-diquinolinacyclotetradecaphanedium ditrifluoroacetate (UCL 1848), indicating that SK channels are normally active in moderating afferent input. Conversely, neuronal responses evoked by mechanical stimuli are inhibited when SK channel activity is increased with 1-EBIO. These effects are reversed by the subsequent application of UCL 1848. Our data demonstrate that SK channels have an important role in controlling sensory input into the spinal cord.
\end{abstract}

Key words: apamin; dorsal root ganglion; sensory transmission; afterhyperpolarization; C-fiber; $\mathrm{K}^{+}$channel

\section{Introduction}

There is a great deal of information about the important roles played by sodium and calcium ion channels in dorsal root ganglion (DRG) neurons, whereas, by comparison, the role(s) of small-conductance and intermediate-conductance calciumactivated potassium channels (SK and IK channels) remains poorly understood. Three mammalian genes (SK1-3/KCNN1-3/ $\left.K_{C a} 2.1,2.2,2.3\right)$ produce subunits of small-conductance calciumactivated potassium channels. A closely related gene (IK1/SK4/ $\left.\mathrm{KCNN} 4 / \mathrm{K}_{\mathrm{Ca}} 3.1\right)$ encodes intermediate-conductance calciumactivated potassium channels. SK channels are widely expressed in both the CNS and peripheral nervous system and are also found in many other tissues (Kohler et al., 1996; Stocker and Pedarzani, 2000). In contrast, IK1 is functionally important for a much more limited range of neurons (Greffrath et al., 1998), although, like the SK channels, IK channels are important in many non-neuronal tissues.

\footnotetext{
Received Aug. 20, 2004; revised Feb. 14, 2005; accepted Feb. 15, 2005.

P.K.B. was awarded an industrial collaborative studentship by the United Kingdom Medical Research Council. R.S is funded by the Wellcome Trust. We thank David Robinson for help with the in vitro spinal cord recordings and Jacqueline Liew and Chris Plumpton for help with the antibody work. We also thank Dennis Haylett and Don Jenkinson for helpful comments while preparing this manuscript and David Colquhoun for advice regarding the statistical analysis.

Correspondence should be addressed to Dr. Guy Moss, Department of Pharmacology, University College London, Gower Street, London WC1E 6BT, UK. E-mail: g.moss@ucl.ac.uk.

DOI:10.1523/JNEUROSCI.0597-05.2005

Copyright $\odot 2005$ Society for Neuroscience $\quad$ 0270-6474/05/253489-10\$15.00/0
}

SK and IK channel pharmacology has been studied extensively. The activity of both SK and IK channels can be increased by 1-ethyl-2-benzimidazolinone (1-EBIO) at micromolar concentrations (Devor et al., 1996; Pedarzani et al., 2001). Furthermore, channels formed by either SK2 or SK3 subunits are selectively inhibited at nanomolar or subnanomolar concentrations by both peptide toxins such as apamin and small molecule blockers such as 8,14-diaza1,7(1,4)-diquinolinacyclotetradecaphanedium di-trifluoroacetate (UCL 1848) and 6,10-diaza-1,5(1,4)-diquinolina-3(1,3),8(1,4)dibenzenacyclodecaphanedium tritrifluoroacetate hydrate (Banks et al., 1979; Blatz and Magleby, 1986; Chen et al., 2000; Hosseini et al., 2001; Faber and Sah, 2003b). IK channels are insensitive to these blockers. In the rat, it seems likely that SK1 subunits cannot form functional channels by themselves (Benton et al., 2003; D'hoedt et al., 2004; Monaghan et al., 2004). However, they can form functional channels in combination with SK2 (Benton et al., 2003). These heterotetrameric channels are also blocked by apamin and UCL 1848 (Benton et al., 2003).

There are conflicting reports about the involvement of SK and IK channels in sensory pathways. In a number of vertebrate species, including humans, SK and/or IK channels have been reported in DRG neurons (Tokimasa et al., 1990; Lüscher et al., 1994; Gold et al., 1996; Amir and Devor, 1997; Boettger et al., 2002). Some of these reports suggest that the channels contribute to calcium-sensitive postspike hyperpolarizations in the cell body (Tokimasa et al., 1990; Lüscher et al., 1994; Gold et al., 1996; Amir 
and Devor, 1997). However, in other studies, no apamin responses were found (Abdulla and Smith, 2001), and furthermore, some groups report little calcium dependence of the afterhyperpolarizations (AHPs) (Villiere and McLachlan, 1996). Thus, the functional role of SK and IK channels in the transmission of sensory information remains to be clearly defined.

In this study, we examined the expression and localization of SK and IK channels by immunohistochemistry, using subunitspecific antibodies. We also examined their functional role using both in vitro and in vivo electrophysiological techniques. We show that SK channels are activated after sensory stimulation and act to control sensory input into the spinal cord. We also show that increasing SK channel activity is an effective means of reducing nociceptive sensory input after punctate mechanical stimulation. Our data reveal an important role for SK channels in sensory transmission and suggest their potential for analgesic drug therapy.

\section{Materials and Methods}

Rat spinal cord electrophysiology in vitro. Dorsal root-evoked ventral root potentials (DR-VRPs) were recorded from neonatal rat spinal cord using standard in vitro electrophysiological techniques (Otsuka and Konishi, 1974; Thompson et al., 1992). Briefly, spinal cords were isolated from 7 to 12-d-old rats (AHA strain) of either sex, hemisected, and then positioned in a recording chamber that was continually perfused with aerated $\left(95 \% \mathrm{O}_{2} / 5 \% \mathrm{CO}_{2}\right)$ Krebs' solution at a flow rate of 3-4 $\mathrm{ml} / \mathrm{min}$ at room temperature [composed of the following (in $\mathrm{mm}$ ): $124 \mathrm{NaCl}, 1.9 \mathrm{KCl}, 1.3$ $\mathrm{MgSO}_{4}, 26 \mathrm{NaHCO}_{3}, 1.5 \mathrm{KH}_{2} \mathrm{PO}_{4}, 10$ D-glucose, and $\left.2 \mathrm{CaCl}_{2}, \mathrm{pH} 7.4\right]$. Suction electrodes were positioned on a dorsal root (L3-L5) for stimulation and on the corresponding ipsilateral ventral root for recording. The primary afferent dorsal root neurons were stimulated every $120 \mathrm{~s}$ with a single supramaximal intensity pulse $(500 \mu \mathrm{A}, 500 \mu \mathrm{s})$, and the evoked DR-VRP was recorded DC with respect to an $\mathrm{Ag} / \mathrm{AgCl}$ reference bath electrode. The DR-VRP signal was amplified (AxoClamp-2A; Axon Instruments, Union City, CA) and relayed to a computer (Vectra XA P166; Hewlett-Packard, Palo Alto, CA) running a custom data acquisition package (Cord; courtesy of Prof. Eric Frank, University of Pittsburgh, Pittsburgh, PA). The signal was recorded for $20 \mathrm{~s}$ after each stimulus (sampling frequency $20 \mathrm{kHz}$ for the first $100 \mathrm{~ms}$ and $50 \mathrm{~Hz}$ thereon). Three components of the DR-VRP were quantified. First, the lowthreshold, fast A-fiber-mediated monosynaptic reflex (MSR; taken as the peak signal between 1 and $15 \mathrm{~ms}$ ) was quantified. Second, the higherthreshold polysynaptic reflex (taken as the area under the curve 15-100 $\mathrm{ms}$ ) was quantified. Third, the C-fiber-mediated, long-lasting slow VRP (taken as the area under the curve $100 \mathrm{~ms}$ to $20 \mathrm{~s}$ ) was quantified. Once stable signals were obtained, the effect of 1-EBIO (1 mM) was determined by adding it to the perfusate ( $15 \mathrm{~min}$ ).

Rat spinal cord electrophysiology in vivo. Intact anesthetized male Sprague Dawley rats $(200-250 \mathrm{~g})$ were used in all experiments, in accordance with the requirements of the United Kingdom Animals (Scientific Procedures) Act (1966). The rats were anesthetized with halothane (3\%) in $33 \% \mathrm{O}_{2} / 67 \% \mathrm{~N}_{2} \mathrm{O}$, which was reduced to $2 \%$ halothane for the ensuing surgery. The rat's body temperature was regulated using a thermostatic heating blanket, maintaining the core temperature at $37^{\circ} \mathrm{C}$. Tracheal cannulation was used to supply anesthesia throughout the experiment, and the rat was secured in a stereotaxic frame by metal clamps attached to the vertebral column. The spinal cord was exposed via a laminectomy at vertebrae L1-L3. The level of anesthesia was then lowered by reducing the halothane concentration to $\sim 1.6 \%$, which was deemed sufficient to retain a state of complete areflexia. Lamina V-VI wide-dynamic range neurons were recorded using a parylene-coated tungsten electrode, which enabled single-unit extracellular recordings to be made. Recordings were made from one neuron in each animal, and each animal received a single pharmacological treatment. All neurons used in the study had defined receptive fields in the toe regions of the hindpaw. Once a single neuron was isolated, its C-fiber threshold was determined as the current required to elicit an action potential in the $\mathrm{C}$-fiber latency range. In a single test, spinal neurons were activated electrically and naturally using a wide range of noxious and innocuous stimuli. For electrical stimulation, a train of 16 electrical stimuli $(2 \mathrm{~ms}$ wide pulses, $0.5 \mathrm{~Hz})$ at three times the threshold current for C-fibers was delivered via two stimulating needles inserted into the receptive field of the hindpaw. A poststimulus histogram was constructed subsequently from the neuronal responses with components separated on the basis of threshold and latency $\mathrm{A} \beta$ (spikes during the first 0-20 ms), A $\delta$ - (spikes 20-90 ms), and C-fiber (spikes 90-300 ms). Neuronal responses occurring after the C-fiber latency band were taken to be the postdischarge of the cell (spikes 300-800 $\mathrm{ms}$ ). A variety of innocuous and noxious stimuli were used to characterize neuronal responses to natural (mechanical and thermal) stimuli. For heat responses, water at $45^{\circ} \mathrm{C}$ was applied to the center of the receptive field of the hindpaw using a water jet. For mechanical stimulation, a brush was used to gently stroke the hindpaw, and von Frey filaments (Scientific Marketing Associates, Barnet, UK) were applied in ascending order ( 9 then $75 \mathrm{~g}$ ). All stimuli were applied for $10 \mathrm{~s}$ per stimulus, and sufficient interval was left between tests to avoid sensitization. Data were captured and analyzed by a CED 1401 (Cambridge Electronic Design, Cambridge, UK) interface coupled to a computer running Spike 2 software (poststimulus time histogram and rate functions).

In the first experiments, UCL 1848 ( 10 or $50 \mathrm{~nm}$ solution) was applied intrathecally directly onto the spinal cord in a volume of $50 \mu \mathrm{l}(n=6)$. In another group of animals, neurons $(n=3)$ were treated with intrathecal 1-EBIO $(300 \mu \mathrm{M})$, and its effects were reversed with UCL 1848 (10 nм). Before drug administration, three stable control responses were obtained. All drug effects were followed for $40 \mathrm{~min}$ per dose, and tests were performed at $10 \mathrm{~min}$ intervals.

Statistical analysis of in vivo recordings. We tested the responses of each neuron for significance by a randomization method (Colquhoun, 1971). For this purpose, we used the program Rantest written by Prof. David Colquhoun (freely available at http://www.ucl.ac.uk/Pharmacology/ dcpr95.html). The method we applied when using this program was to first calculate the difference between the mean response in predrug controls and the mean response after drug treatment. The program then pools all of the individual responses (i.e., both the predrug and postdrug responses) and reselects, at random, two groups: one equal in size to the predrug control group and the other (consequently) equal in size to the postdrug group. The difference between means for these two new groups is then calculated. This process of random selection and calculation of the difference between means is then repeated 50,000 times, and a histogram of the distribution of differences is computed. Significance is determined from the original difference in means and the distribution of possible differences in means. A 95\% confidence interval was used for significance. This method was chosen because it makes no assumptions about the distribution of the data or the rate of onset (or offset) of drug effects. However, the approach of pooling all responses after the drug application and uncertainty about the speed of drug onset could potentially underestimate the number of significant responses.

Cell lines and transfections. Human embryonic kidney (HEK) 293 cells were maintained in DMEM, supplemented with $10 \%$ fetal calf serum (FCS), $2 \mathrm{~mm}$ L-glutamine, penicillin $(100 \mathrm{U} / \mathrm{ml})$, and streptomycin (100 $\mu \mathrm{g} / \mathrm{ml}$ ). Cells were grown in $35-\mathrm{mm}$-diameter culture dishes to $\sim 70 \%$ confluency, and $1-3 \mu \mathrm{g}$ of SK/IK channel plasmid DNA and $1 \mu \mathrm{g}$ of green fluorescent protein (GFP) plasmid DNA (QBI; QBiogene, Harefield, UK) were transfected using Lipofectamine 2000 according to the manufacturer's instructions. Cells were grown overnight and replated onto laminin-coated square glass coverslips $1 \mathrm{~d}$ before staining. All tissue culture materials were obtained from Invitrogen (San Diego, CA). Mammalian expression plasmids for $S K 1$ and SK2 were a generous gift from Drs. Len Kaczmarek and William Joiner (Yale University, New Haven, CT), the untranslated region of the SK1 clone being modified as reported previously (Benton et al., 2003). The rat SK3 clone was as reported by Hosseini et al. (2001), and the rat $I K$ clone was amplified from rat DRG cDNA and subcloned into pcDNA3.1D/V5-His-TOPO. The sequence of this IK clone is identical to that reported previously under GenBank accession number Q9QYW1.

DRG culture. Sprague Dawley rats [postnatal day 45 (P45) for staining and P17 or P45 for electrophysiology] of either sex were killed in accordance with Home Office guidelines for Schedule 1 killing. The dorsal root 


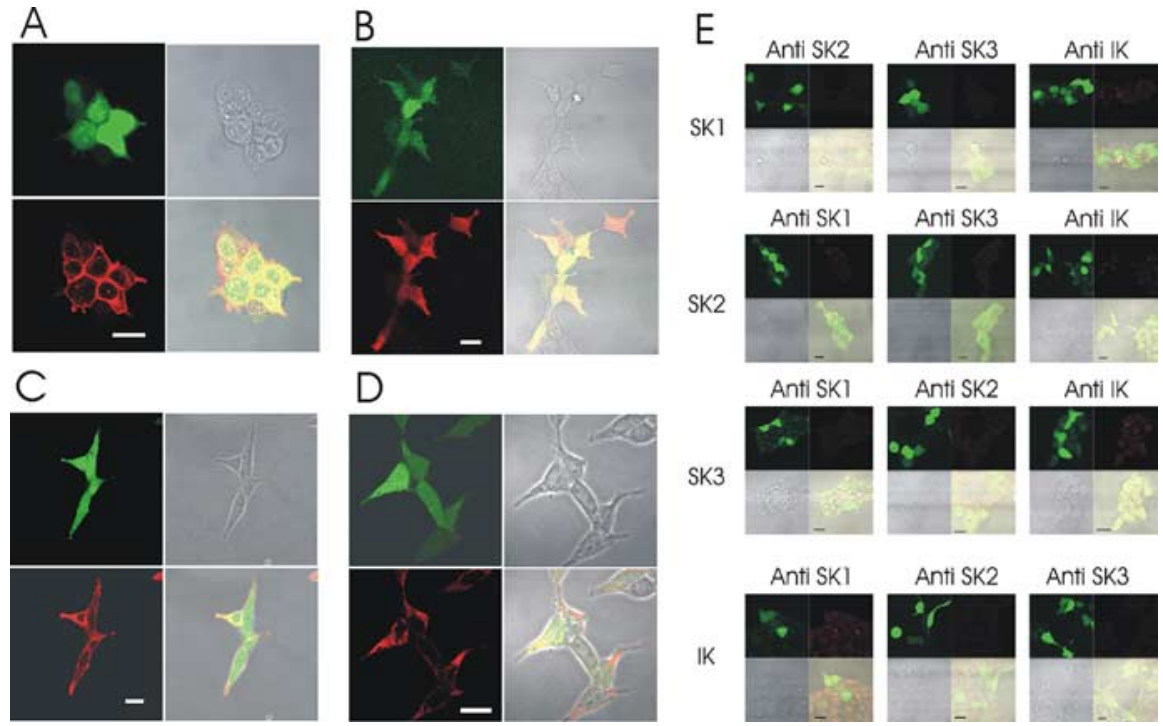

Figure 1. Specificity of the rat SK and IK channel subunits tested on HEK 293 cells transfected with rat SK and IK channe constructs. A-D, Positive controls are shown. Each group of four images shows GFP fluorescence in the top left panel (indicating positive transfection), the bright-field image (top right), the antibody stain (bottom left), and an overlay of all three images (bottom right). $\boldsymbol{A}$, Staining with the IK1 antibody. B, Staining with the SK1 antibody. C, Staining with the SK3 antibody. D, Staining with the SK2 antibody. $\boldsymbol{E}$, Negative controls. Each panel shows GFP staining (top left) antibody staining (top right), bright-field image (bottom left), and an overlay of all channels (bottom right). For each panel, the transfected subunit is listed at the far left of the row, whereas the antibody used for staining is listed above the panel. Scale bars, $20 \mu \mathrm{m}$.

ganglia were dissected out and placed in Leibovitz's L-15 medium. The nerve roots were trimmed off so that only the ganglia remained. The ganglia were next washed twice in $\mathrm{Ca}^{2+}$ - and $\mathrm{Mg}^{2+}$-free HBSS (Invitrogen). The ganglia were then incubated in HBSS buffered with $10 \mathrm{~mm}$ HEPES and containing $400 \mathrm{U} / \mathrm{ml}$ type 1 A collagenase (Sigma, St. Louis, $\mathrm{MO}$ ) and $6 \mathrm{mg} / \mathrm{ml}$ bovine serum albumin (BSA) for $20 \mathrm{~min}$ at $37^{\circ} \mathrm{C}$. After the incubation period, ganglia were washed twice in $10 \mathrm{mM}$ HEPESbuffered HBSS. They then underwent a second incubation in HEPESbuffered HBSS, this time containing $1 \mathrm{mg} / \mathrm{ml}$ trypsin and $6 \mathrm{mg} / \mathrm{ml} \mathrm{BSA}$ for $30 \mathrm{~min}$ at $37^{\circ} \mathrm{C}$. The cells were then transferred to a growth medium consisting of L-15 medium supplemented with $10 \%$ FCS, $0.6 \% \mathrm{w} / \mathrm{v}$ D-glucose, $0.19 \% \mathrm{w} / \mathrm{v} \mathrm{NaHCO} 3,100 \mathrm{U} / \mathrm{ml}$ penicillin, $100 \mu \mathrm{g} / \mathrm{ml}$ streptomycin, and $50 \mathrm{ng} / \mathrm{ml}$ nerve growth factor. The cell suspension was finally plated onto laminin-coated glass coverslips. Cells were used for staining $1 \mathrm{~d}$ after plating for antibody staining and $1-3 \mathrm{~d}$ after plating for electrophysiology.

AHP recording from cultured DRG neurons. Recordings were made using either intracellular electrodes or by perforated patch (amphotericin B; $0.12 \mathrm{mg} / \mathrm{ml}$ ). Patch electrodes were filled with a solution composed of the following (in mM): $126 \mathrm{KMeSO}_{4}, 14 \mathrm{KCl}, 10 \mathrm{HEPES}$, and $3 \mathrm{MgCl}_{2}$, $\mathrm{pH} 7.25$, and had resistances of 3-5 $\mathrm{M} \Omega$ in this solution. Intracellular electrodes were filled with a solution of $1 \mathrm{M} \mathrm{KCl}$ and had resistances of $90-150 \mathrm{M} \Omega$. All recordings were made using the Axoclamp 2A amplifier (Axon Instruments) in bridge mode. After cell penetration with an intracellular electrode or permeabilization using a patch electrode, the membrane potential was allowed to stabilize for at least $5 \mathrm{~min}$ before characterization. For these recordings, the bath solution contained the following (in mM): $130 \mathrm{NaCl}, 3 \mathrm{KCl}, 2.5 \mathrm{CaCl}_{2}, 1.2 \mathrm{MgCl}_{2}, 5$ glucose, and $10 \mathrm{NaHCO}_{3}$, maintained at $\mathrm{pH} 7.5$ by bubbling with $95 \% \mathrm{O}_{2} / 5 \% \mathrm{CO}_{2}$. Cells were only deemed suitable for study if the membrane potential was more negative than or equal to $-50 \mathrm{mV}$. Recordings were made at $32^{\circ} \mathrm{C}$.

Production of antibodies. Polyclonal rabbit antibodies were raised against peptide sequences CSPQSHWLPTTASDYG for the anti-rSK1 antibody (Rb200); CRRSSSTAPPTSSESS for the anti-rSK2 antibody (M1); DTSGHFHDSGVGDLDC for the anti-rSK3 antibody (M75); and CQPPEPIQEAT for the anti IK antibody (R212). Rabbit antisera was assayed by ELISA, and the IgG fraction of the serum was purified on a protein A-Sepharose affinity column. Antibodies were subsequently further purified on a peptide-affinity column.
Antibody staining of cells. All staining was performed at room temperature $\left(22^{\circ} \mathrm{C}\right)$. Cells were first washed three times in PBS [composed of the following (in $\mathrm{mm}$ ): $136.9 \mathrm{NaCl}, 2.7$ $\mathrm{KCl}, 9.2 \mathrm{Na}_{2} \mathrm{HPO}_{4}, 1.8 \mathrm{KH}_{2} \mathrm{PO}_{4}$, pH to 7.2 with $\mathrm{HCl}$. Next, the cells were fixed in PBS containing $4 \%$ paraformaldehyde for $10 \mathrm{~min}$. Coverslips were then transferred to PBS only for 5 min to allow the cells to rehydrate. After this, cells were permeabilized in methanol for 10 min followed by a 5 min wash in PBS. Next, the cells were incubated in an antibody blocking solution ( $2 \%$ horse serum, $2 \%$ BSA; Sigma) in PBS for $1 \mathrm{~h}$. Cells were then incubated in the appropriate primary antibody for $4 \mathrm{~h}$. The $4 \mathrm{~h}$ incubation was followed by three washes in a PBS solution containing 1\% Tween 20. The cells were then incubated in a solution containing a fluorescently labeled secondary antibody for $1 \mathrm{~h}$. The cells finally underwent three washes in PBS (containing 1\% Tween 20), and the coverslips were mounted onto clean glass slides using an antifade mount (Vectashield; Vector Laboratories, Burlingame, CA). We estimated the number of cells staining positively for SK3 in our DRG cultures by counting positive cells using confocal images. For this purpose, we plated cells on CELLocate coverslips (Eppendorf, Hamburg, Germany) to prevent them being counted twice. To account for cells in different optical planes, we determined the highest intensity signal for each cell by focusing through the field on multiple planes.

Immunohistochemistry. Sprague Dawley rats ( $45 \mathrm{~d}$ of age) of either sex were anesthetized deeply using $0.5 \mathrm{mg} / \mathrm{kg}$ hypnorm (fentanyl citrate and fluanisone) and $2.5 \mathrm{mg} / \mathrm{kg}$ diazepam. They then underwent transcardial perfusion with saline before a 15 min perfusion with $4 \%$ paraformaldehyde in $0.1 \mathrm{M}$ phosphate buffer $\left(\mathrm{PB} ; 124 \mathrm{~g} / \mathrm{L} \mathrm{Na}_{2} \mathrm{HPO}_{4}\right.$ and $15.6 \mathrm{~g} / \mathrm{L}$ $\mathrm{NaH}_{2} \mathrm{PO}_{4}$ with $0.1 \%$ sodium azide, final $\mathrm{pH}$ of 7.4). After the perfusion, the lumbar section of the spinal cord was dissected out and fixed for an additional $4 \mathrm{~h}$ in $4 \%$ paraformaldehyde solution. The cords were then transferred to $30 \%$ sucrose and stored at $4^{\circ} \mathrm{C}$ overnight. Serial transverse slices of $40 \mu \mathrm{m}$ were cut using a freezing microtome.

Slices were transferred to separate wells of a four-well culture dish. They were incubated first in blocking solution consisting of $3 \%$ goat serum and $0.3 \%$ Triton X-100 in PB and left on a horizontal shaker for $1 \mathrm{~h}$. Primary antibodies were made up to the required concentration in the blocking solution and added to the slices, which were then left shaking overnight. Tissues next underwent three separate washes in PBS. Slices were then incubated with secondary antibodies in blocking solution (as above) for $2 \mathrm{~h}$. After a final three washes in PBS, slices were mounted onto $0.5 \%$ gelatin-coated glass slides using Vectashield antifade mount.

Slices and stained cells were viewed on either a Zeiss (Oberkochen, Germany) LSM 510 microscope or on a Leica (Nussloch, Germany) TCS confocal microscope.

\section{Results}

\section{SK channel antibodies for immunohistochemistry}

We have developed a range of polyclonal rabbit antibodies against SK and IK channel subunits. To examine the suitability of these antibodies for immunohistochemistry experiments, we stained HEK 293 cells transfected with the appropriate rat SK or IK expression construct (along with GFP as a transfection marker). The results are shown in Figure 1. For each SK/IK protein, a positive staining pattern is observed in appropriately trans- 
fected cells. Furthermore, there is no signal in cells transfected with any of the other (closely related) SK/IK channels, demonstrating that the antibody recognition is subunit specific. As expected, there are some differences in the subcellular distributions of these SK channel subunits. For example, SK3 tends to produce a stronger signal toward the edge of the cell at, or close to, the cell membrane, whereas the SK1 and SK2 subunits are usually distributed more widely across the cell interior (Fig. $1 B-D)$. The subcellular distributions for SK1, 2, and 3 shown in Figure 1 are consistent with previous observations made by our group and by others using antibodies to different SK channel epitopes and thus confirm that there are important differences in subunit trafficking (Cingolani et al., 2002; Benton et al., 2003; D'hoedt et al., 2004).

\section{Rat spinal cord sections stain positively for SK3 and IK protein subunits}

We examined the expression of SK and IK channels in vivo by using the anti-SK/IK channel antibodies to stain rat spinal cord slices. A robust signal was produced with the SK3 antibody. As shown in Figure 2, $A$ and $B$, SK3 immunoreactivity is found in a number of regions within the spinal cord. From the perspective of sensory neuron transmission, the most important signal is the SK3 antibody staining seen in the dorsal horn (Fig. $2 A, D$ ). This is a diffuse staining pattern, which is most intense in laminas I, II, and III. We examined the pattern of SK3 immunoreactivity in some detail by comparing it with that of the nociceptive heat receptor VR1 (TRPV1), which is expressed in laminas I and IIi (Tominaga et al., 1998; Guo et al., 1999). As reported by others, VR1 immunoreactivity reveals high levels of expression in the laterally running fibers of lamina I of the spinal cord, whereas a clear, although weaker, signal is seen in lamina IIi (Fig. 2C). There is considerable overlap in the regions staining positively for VR1 and SK3. Nevertheless, the patterns of expression are clearly different. First, immunoreactivity for VR1 is most prominent in lamina I, whereas for SK3 it is most prominent in lamina II. Second, the SK3 antibody staining has a wider distribution, extending across lamina II and below the VR1 staining, entering lamina III and deeper, where larger-diameter afferents terminate (Fig. $2 A, F$ ). Based on their patterns of immunoreactivity, VR1 and SK3 might sometimes participate in the same sensory responses, but the wider distribution of SK3 immunoreactivity in these outer laminas suggests that it might participate in a broader range of both nociceptive and nonnociceptive sensory transmission.

Other regions of the spinal cord also stain positively with the SK3 antibody. One example is seen in the ependymal cells that line the central canal (Fig. $2 G, H$ ). In this regard, it is interesting that SK3 expression has been reported in other epithelial cell types (Rhodes et al., 2003). Also of interest is the positive SK3 immunoreactivity in the motoneuron regions of the ventral horn. Here, the signal can be seen in both the cell bodies and processes (Fig. 2I,J), rather as it is in SCG neurons (Hosseini et al., 2001). Furthermore, motoneurons, like SCG neurons, are reported to produce apamin-sensitive afterhyperpolarizations (Zhang and Krnjevic, 1987; Hounsgaard et al., 1988). Thus, it may well be that SK3 subunits are a component of the channels that underlie these AHPs.

The IK1 antibody also produced strong staining in rat spinal cord sections but with a different distribution that was clearly associated with cell bodies throughout the spinal cord. Examples of the IK1 antibody immunoreactivity are shown in Figure 3. It is intense in the ependymal cells around the central canal of the
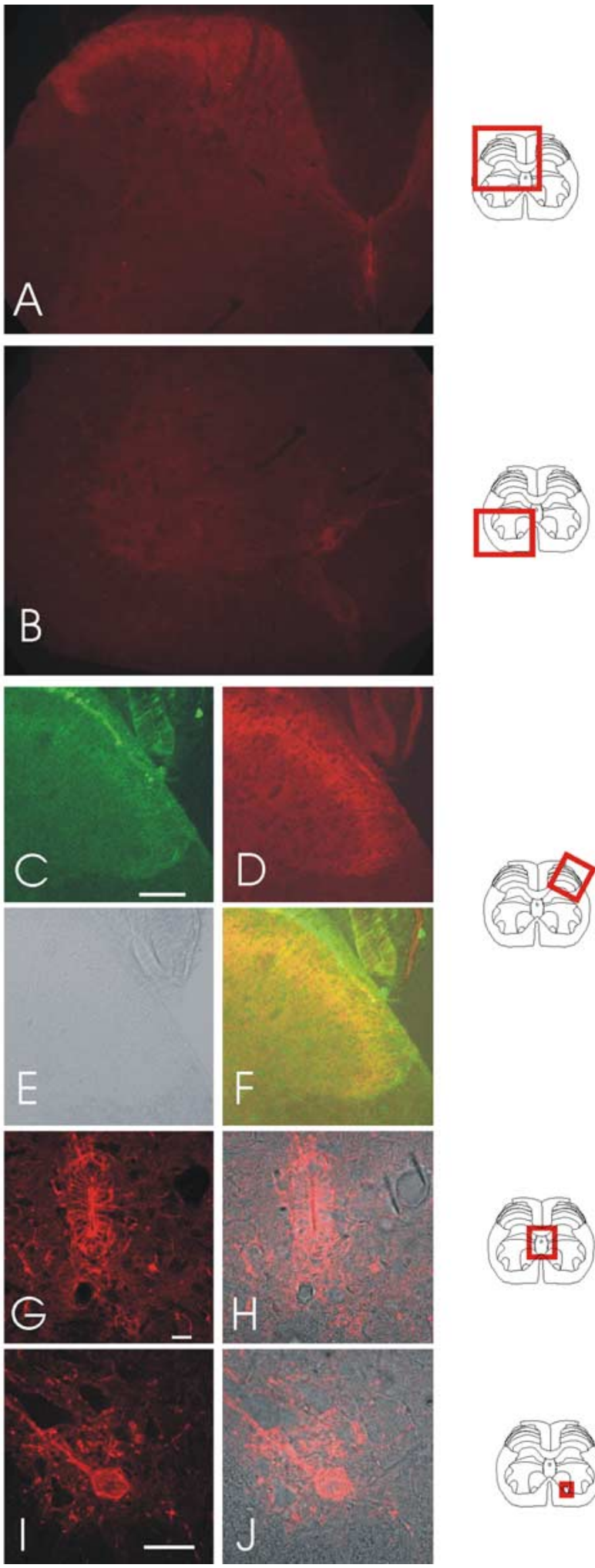

Figure 2. SK3 staining in spinal cord slices with positions indicated by diagrams on the right side. $\boldsymbol{A}, \boldsymbol{B}$, Standard fluorescent low-magnification views of SK3 staining in the dorsal and ventral horns of the spinal cord. $\boldsymbol{C}$, Higher-resolution confocal images of the dorsal horn of rat lumbar spinal sections with stained with the VR1 antibody. D, SK3 staining of the same section. $\boldsymbol{E}$, A bright-field image of the section shown in $\boldsymbol{C}$ and $\boldsymbol{D}$. $\boldsymbol{F}, \mathrm{An}$ overlay of VR1, SK3, and bright-field images. G, SK3 staining of the ependymal cells of the spinal cord. $\boldsymbol{H}$, SK3 staining from $\boldsymbol{G}$ overlaid with the bright-field image. $\boldsymbol{I}$, An example of SK3 staining in the motoneuron region of the ventral horn. SK3 protein appears in both cell bodies and processes. J, The SK3 staining in I overlaid with the bright-field image. Scale bars: $C, 100 \mu \mathrm{m} ; \mathbf{G}, 20 \mu \mathrm{m} ; \boldsymbol{I}, 50 \mu \mathrm{m}$. 

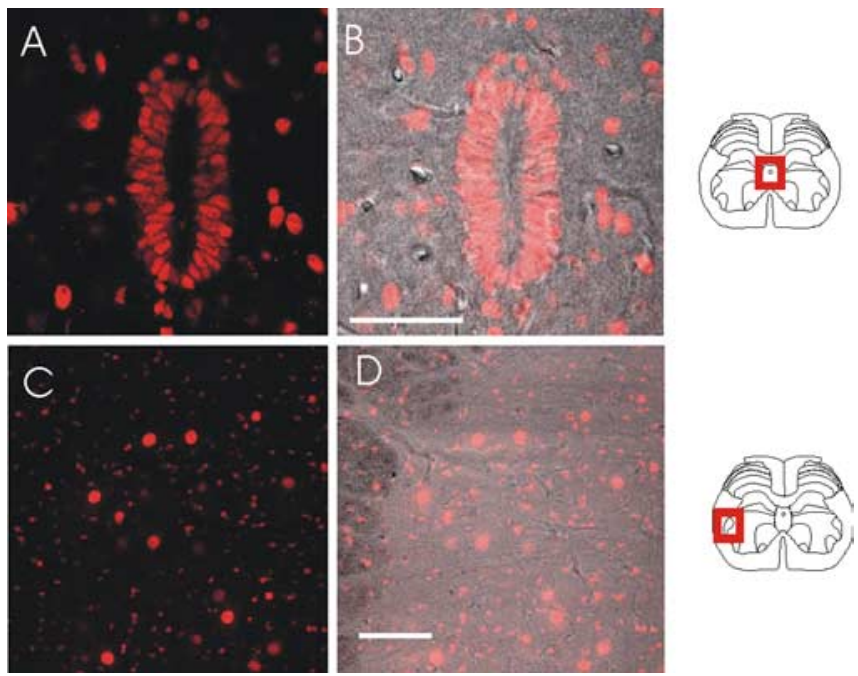

Figure 3. Staining for IK1 in rat spinal cord lumbar sections. $A$, Staining of the ependymal cells surrounding the central canal and cell bodies scattered throughout the spinal cord. $\boldsymbol{B}$, Ependymal cell staining overlaid with the bright-field image. $C$, Additional examples of the IK1-positive cells, this time in the ventral horn. $\boldsymbol{D}$, Staining of $\boldsymbol{C}$ overlaid with a bright-field image. Scale bars: (in $\boldsymbol{B}, \boldsymbol{D}) 50 \mu \mathrm{m}$. Diagrams on the right indicate the position of the field shown.

spinal cord (Fig. $3 A, B$ ). As with the staining for SK3, the ependymal cells, by expressing IK1, are like other types of epithelial cells, which have been reported to express similarly high levels of the SK and IK channels (MacVinish et al., 1998; Furness et al., 2003; Rhodes et al., 2003). In addition, IK immunoreactivity also appears in the bodies of cells scattered throughout the spinal cord (Fig. $3 A-D$ ). An example of these IK-positive cells in the ventral horn is shown in Figure 3, $C$ and $D$, and they can also be seen scattered around the ependymal cells (Fig. $3 A, B$ ). We have not attempted to identify the other cell type(s) staining positively with the IK antibody. However, IK1 spinal-cord immunoreactivity is associated clearly with cell bodies and is very different from the SK3 antibody immunoreactivity so likely reflects a difference in the functional roles of SK and IK channels.

In contrast to the strong SK3 and IK1 immunoreactivities, levels of SK2 and SK1 immunoreactivity were too low to provide distinct staining pattern in the spinal cord at the antibody concentrations used to stain transfected HEK 293 cells (Fig. 4). However, at higher concentrations, the SK2 antibody appears to stain fibers selectively within lamina I and II as well as some large cells in the ventral horn, whereas the SK1 antibody stains cells throughout the spinal cord. Given these observations, we cannot rule out either the possibility that there are lower levels of SK1 and SK2 protein expression in the spinal cord, or that, compared with the SK3 and IK channel antibodies, our SK1 and SK2 antibodies have lower affinities for their target proteins (see Discussion).

Neurons from dorsal root ganglia express SK3 in peripherinpositive and peripherin-negative cell types

The SK3 immunoreactivity in laminas I, II, and III suggests that this protein might be expressed in DRG sensory neurons that terminate in the dorsal horn. We therefore examined the expression of SK3 in DRG neurons. To identify particular sensory cell types, we stained cultured rat DRG cells with both SK3 and peripherin, a marker of small (C-type) neurons (Oblinger et al., 1989; Goldstein et al., 1991). An example of the staining we observed is shown in Figure 5. SK3 immunoreactivity is clearly
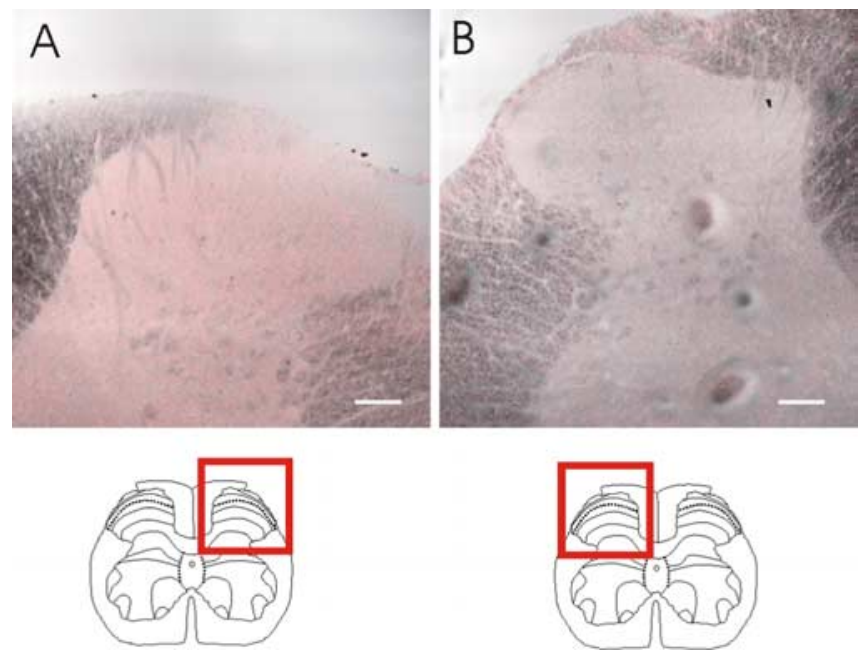

Figure 4. Dorsal horn region of the spinal cord, stained with SK1 and SK2 antibodies. A specific stain was not seen for SK1 $(\boldsymbol{A})$ or SK2 $(\boldsymbol{B})$ at concentrations that produced a signal in transfected HEK 293 cells (Fig. 1). Scale bars, $100 \mu \mathrm{m}$.

present in peripherin-positive neurons and also in many larger, peripherin-negative (A-type) neurons. In addition to those cells showing a positive stain for SK3, both the peripherin-positive and the peripherin-negative cell populations contained neurons that were not clearly stained with the SK3 antibody under our culture conditions. Indeed, in our adult DRG cultures, $\sim 50 \%$ of neurons provide an unambiguously positive stain for SK3, and of these SK3-positive cells, $\sim 40 \%$ also stain positively for peripherin. Importantly, the observation that SK3 immunoreactivity is present in large-diameter peripherin-negative cells (Fig. 5) suggests that this channel may have a role in low-threshold $A \beta$ fibers. The fact that many smaller, peripherin-positive and some peripherinnegative cells stain positively suggests that SK3 could also be important for the transduction of nociceptive sensory signals primarily carried by A $\delta$ and C-type fibers. Furthermore, the SK3 immunoreactivity in this variety of cell types is consistent with the distribution of SK3 antibody staining in the spinal cord, because nociceptive neurons terminate in lamina I and II, whereas $\mathrm{A} \beta$ fibers terminate in lamina III and deeper.

\section{SK channels modulate sensory pathways in vitro}

In recordings from cultured DRG neurons, we observed responses that are consistent with SK channels forming a component of the AHP in some neurons (Fig. 5E,F). However, the AHPs were variable in both magnitude and duration, and responses were infrequent; they did not occur as often as might be expected by the antibody staining. Under our culture conditions, $\sim 5 \%$ of neuronal medium AHPs responded to the application of UCL 1848 or 1-EBIO. It is possible that recordings made in voltage clamp could reduce some of the variability that we see among these DRG responses (and consequently may reveal a higher fraction of cells with SK-like behavior), but it seems clear that SK channels are not the main mediators of DRG afterhyperpolarizations in the cell body. Nevertheless, the observation that SK3 appears to be present in the outer laminas of the spinal cord and in DRG cell bodies raises the possibility that the main function of SK channels occurs elsewhere in the cell, perhaps when transported out of the cell body and into the spinal cord. Alternatively, the SK-like immunoreactivity in the spinal cord could reflect postsynaptically expressed SK channels, or indeed both presynaptic and postsynaptic SK channel expression could contribute. 

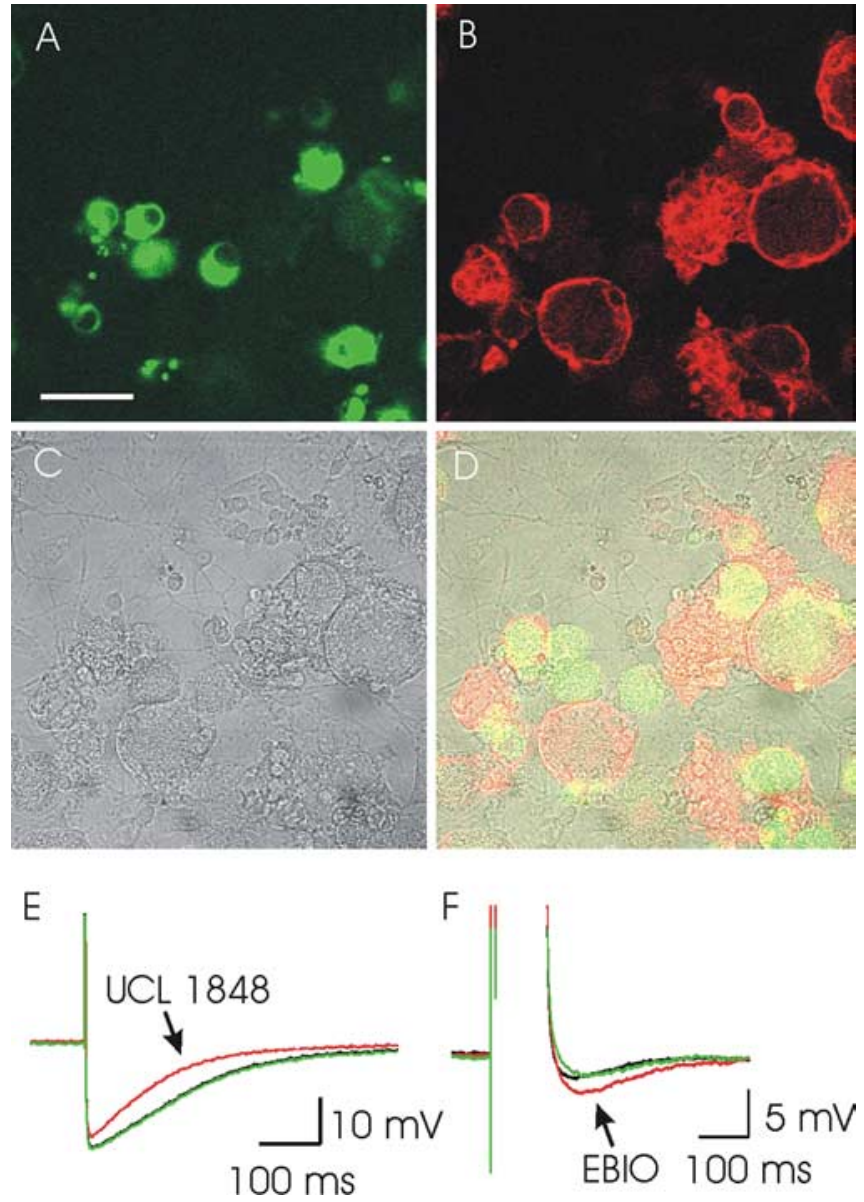

Figure 5. SK3 immunofluorescent antibody staining and AHP pharmacology of rat DRG cells in culture. $A$, Peripherin staining of DRG cells in culture (green). Intense staining for this marker is limited to small-diameter cells $(\leq 25 \mu \mathrm{m}$ ). $\boldsymbol{B}$, SK3 staining (red). Both large- and smalldiameter DRG neurons stain positively. $C$, A bright-field image of the same field of cells. $D$, An overlay of images $\boldsymbol{A}-\boldsymbol{C}$. SK3 can be seen in both peripherin-positive and peripherin-negative cells. Scale bar, $50 \mu \mathrm{m}$. $\boldsymbol{E}$, An AHP recorded from a DRG neuron showing a component that is sensitive to block by UCL 1848 (10 nM). The recording was made using the perforated patch configuration. $\boldsymbol{F}$, An AHP recorded from a cultured rat DRG neuron showing activation in response to $300 \mu \mathrm{m}$ 1-EBI0 (EBI0). This recording was made using an intracellular electrode to inject a depolarizing current pulse and hence to stimulate the cell AHP. Both $\boldsymbol{E}$ and $\boldsymbol{F}$ are the averages of three successive responses to a single action potential $(\boldsymbol{E})$ or a depolarizing pulse $(\boldsymbol{F})$. For both $\boldsymbol{E}$ and $\boldsymbol{F}$, the AHP before drug application is shown in black, the AHP after drug application is shown in red, and the AHP after drug washout is shown in green.

In either case, if a substantial functional role of SK channels resides in the spinal cord, then modulators such as 1-EBIO could perhaps be used to increase their activity and thus reduce sensory input. This assumes of course that the channels are not already, under normal circumstances, maximally active and that the increased SK channel activity would be sufficient to significantly affect the membrane potential of the cell. Therefore, to determine the effect of modulating SK channel activity, we first recorded sensory responses in vitro by measuring the effect of 1-EBIO on DR-VRPs in the rat spinal cord preparation (Otsuka and Konishi, 1974; Thompson et al., 1992). As shown in Figure 6, 1-EBIO (1 $\mathrm{mm}$ ) suppressed all components of the dorsal root-evoked ventral root potential, but inhibition of the slow, high-threshold C-fiber component ( $87 \pm 5 \% ; n=3$ ) was almost complete and substantially greater than that of the fast, low-threshold A-fibermediated component $(18 \pm 6 \%)$ and the $\mathrm{A} \beta / \mathrm{A} \delta$ polysynaptic component $(32 \pm 8 \%)$. Partial reversal of these responses was
A
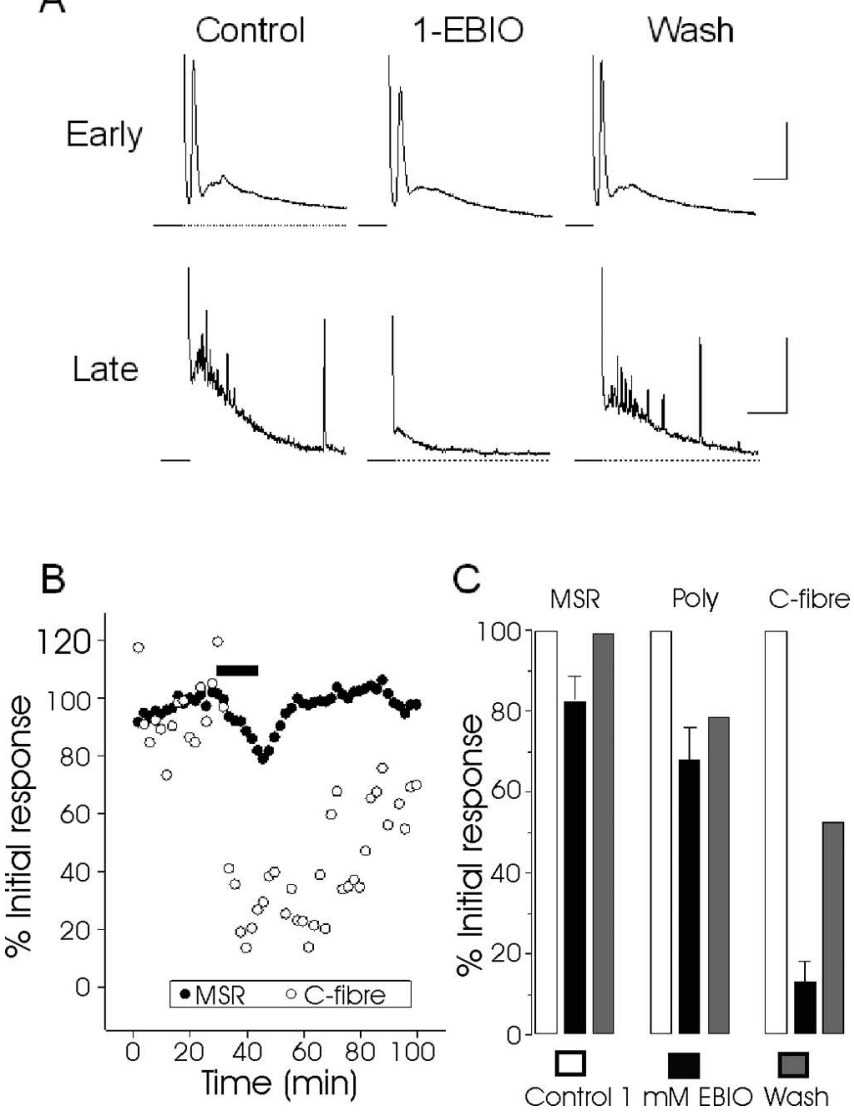

Figure 6. Modulation of synaptic transmission in the neonatal rat spinal cord in vitro by $1-E B I 0$. The traces show ventral root potentials evoked by dorsal root stimulation. $\boldsymbol{A}$, Representative recordings of DR-VRPs in the absence (control) and presence of 1-EBI0 (1 mM) and after washout. Note the small, reversible reduction of the early components of the VRP (monosynaptic and polysynaptic reflex) by 1-EBI0 and the much more marked attenuation of the late component (C-fiber; slow). Calibration for the early phase is $10 \mathrm{~ms}$ and $0.5 \mathrm{mV}$, whereas for the late phase it is $2 \mathrm{~s}$ and $0.2 \mathrm{mV}$. B, A typical time course of 1-EBIO (EBI0) action. The drug was present for the time indicated by the solid bar. The peak MSR amplitude (solid circles) and the (-fiber slow VRP area (open circles) were normalized to the control values obtained immediately before EBIO addition. Data for the polysynaptic reflex are omitted for clarity. C, Mean data from three experiments (vertical bars show SEM) for the MSR, polysynaptic response (Poly) (area 15-100 ms), and the slow C-fiber-mediated VRP.

observed on washout (Fig. 6). Given that increasing SK channel activity appears to modulate spinal cord sensory responses in vitro, we pursued these findings by examining the effects of modulating SK channel activity in vivo.

SK channels control sensory input into the spinal cord in vivo We used extracellular recording from single lamina $\mathrm{V}$ wide dynamic range neurons in the anesthetized rat to study the physiological role of SK channels in vivo (Urch and Dickenson, 2003). The potential for SK channels to control spinal cord sensory input was first examined by comparing the number of action potentials evoked by afferent stimulation before and after application of the SK blocker UCL 1848. To maintain the specificity of action, low concentrations of UCL 1848 (10 or $50 \mathrm{~nm}$ ) were applied directly onto the surface of the exposed cord. UCL 1848 produced dose-related facilitation of the electrically evoked responses. Under these conditions, block of SK channels produced a statistically significant increase in the C-fiber-evoked responses in four of six neurons (at the 5\% level). (One neuron showed a modest but significant decrease that was not dose dependent and 

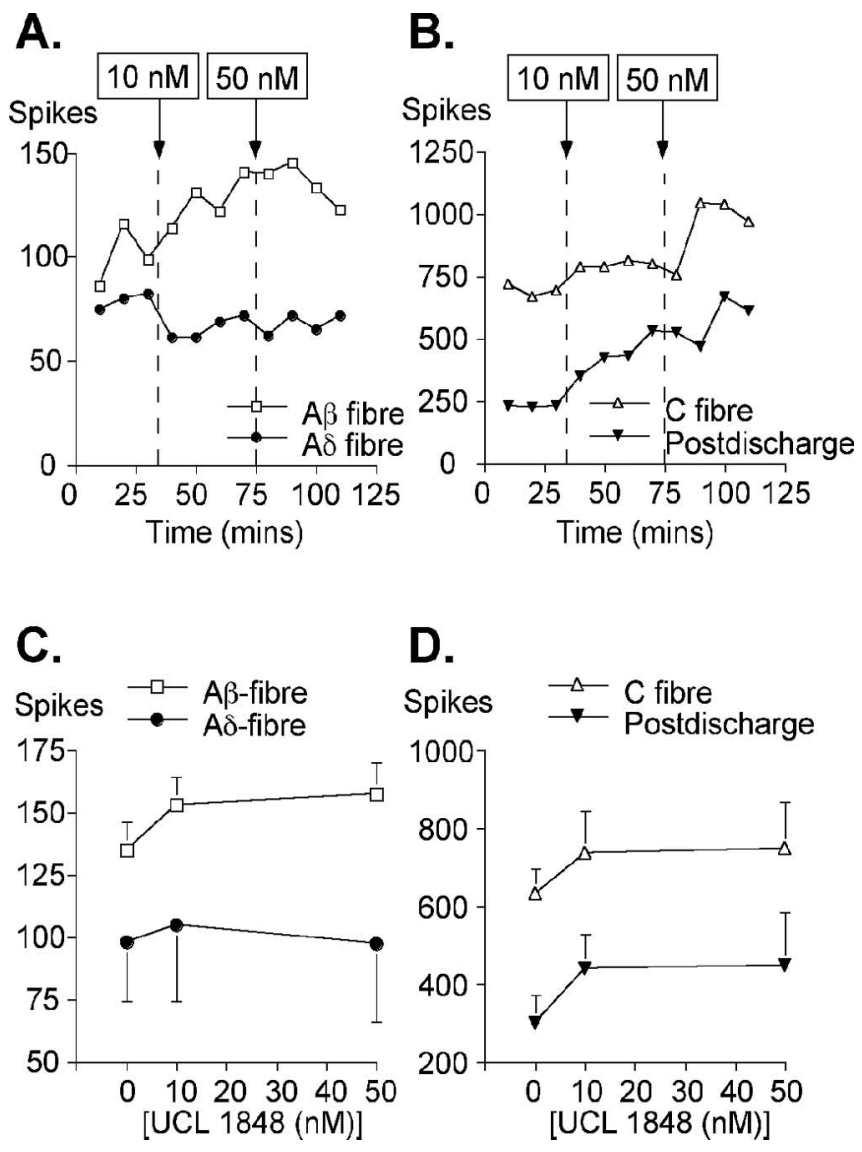

Figure 7. The effect of $S K$ channel block on electrically stimulated afferent fiber input measured in lamina $V$ wide dynamic range dorsal horn neurons. $A$, Examples of the $A \beta$-fiber (open squares) and $A \delta$-fiber (filled circles) input recorded from single neurons, before and after the application of UCL 1848. B, Examples of electrically stimulated input from C-fibers (open triangles) and in the postdischarge (filled triangles) before and after the application of UCL 1848. For both $\boldsymbol{A}$ and $\boldsymbol{B}$, the dashed line indicates the point of drug addition (at either 10 or $50 \mathrm{~nm}$ concentrations). $\boldsymbol{C}$, The averaged responses seen in $A \beta$ - and $A \delta$-fiber input $(n=6)$. $\boldsymbol{D}$, The averaged responses seen in $\mathbf{C}$-fibers and in the postdischarge $(n=6)$. For both $\boldsymbol{C}$ and $\boldsymbol{D}$, the mean $\pm S E$ is shown for each dose.

one showed no trend.) Similarly, sensory responses evoked via $\mathrm{A} \beta$-fibers also increased, with three of six neurons showing an increase significant at the $5 \%$ level and with a clear trend present when all the data are averaged (Fig. 7). Similar effects were also observed with the postdischarge of spinal neurons (a measure of neuronal "wind-up"), in which three of six neurons showed responses that were significant at the $5 \%$ level, and the average data again showed a clear upward trend. Although two neurons also showed a significant increase in A $\delta$ responses after the application of UCL 1848, one neuron showed a small decrease, and the averaged data showed no trend (Fig. $7 A, C$ ). The breadth of UCL 1848 effects among these various types of afferent input is consistent with the spinal cord staining, which indicates that both C-type and A-type sensory inputs are likely to come under SK channel regulation. However, the effects of UCL 1848 on electrically evoked responses were obtained using suprathreshold stimuli. Therefore, to ascertain the physiological relevance of these effects, we next tested UCL 1848, over the same dose range, using natural stimuli to evoke responses.

The effects of UCL 1848 on naturally evoked responses to stimulation by brush, von Frey $9 \mathrm{~g}$ fiber, von Frey $75 \mathrm{~g}$ fiber, and heat are summarized in Figure 8. UCL 1848 produced a marked facilitation of the naturally evoked responses, and this was most
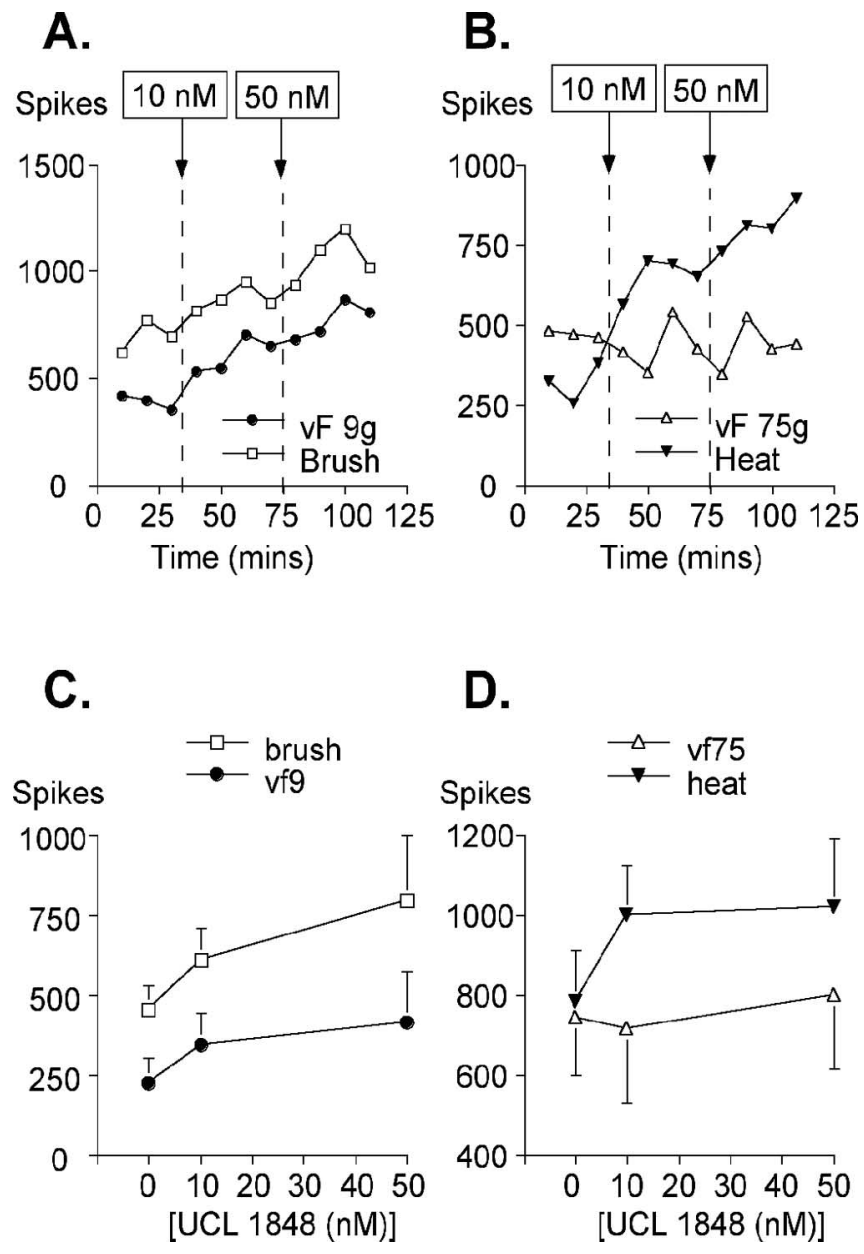

Figure 8. The effect of SK channel block on naturally stimulated afferent fiber input measured in lamina $V$ wide dynamic range neurons. $\boldsymbol{A}$, Examples of the responses to brush (open squares) and von Frey (vF) $9 \mathrm{~g}$ (filled circles) stimuli recorded from single neurons before and after the application of UCL 1848. B , Examples of responses to nociceptive heat (filled triangles) and von Frey (vF) $75 \mathrm{~g}$ (open triangles) stimuli recorded single neurons before and after the application of UCL 1848. For both $\boldsymbol{A}$ and $\boldsymbol{B}$, the dashed line indicates the point of drug addition (at either 10 or $50 \mathrm{~nm}$ concentrations). $\boldsymbol{C}$, The averaged responses seen after stimulation by brush or by von Frey (vf) $9 \mathrm{~g}$ fiber ( $n=5$ and 6 , respectively). $\boldsymbol{D}$, The averaged responses seen after stimulation by heat or by von Frey $(\mathrm{vf}) 75 \mathrm{~g}(n=6)$. For both $\boldsymbol{C}$ and $\boldsymbol{D}$, the mean $\pm \mathrm{SE}$ is shown for each dose.

prominent with the innocuous mechanical punctate stimulus von Frey $9 \mathrm{~g}$ (three of six neurons showing an increase significant at the 5\% level) and the dynamic stimulus brush (three of five neurons showing an increase that was significant at the 5\% level). Averaging all the data these low-threshold responses were enhanced by 1.6- to 1.8-fold after drug administration (Fig. $8 \mathrm{~A}, \mathrm{C}$ ). This was in contrast to the lack of drug effect seen on responses evoked by the noxious von Frey $75 \mathrm{~g}$ stimulus, in which only one neuron showed a statistically significant increase at the $5 \%$ level (Fig. $8 B, D$ ). However, with this intense stimulus, producing activity at the top of the mechanical coding range of the neurons, the lack of effect of UCL 1848 solely on this measure likely relates to an inability of the neurone to exhibit any additional increase in activity. Finally, neuronal responses to noxious heat were also facilitated significantly in three of six neurons after the application of UCL 1848. Again, the averaged data show a clear increase (Fig. $8 B, D$ ). Given the very low concentrations and volumes of drug applied, our data clearly indicate that SK channels are activated normally by peripheral stimulation, and this raises the pos- 

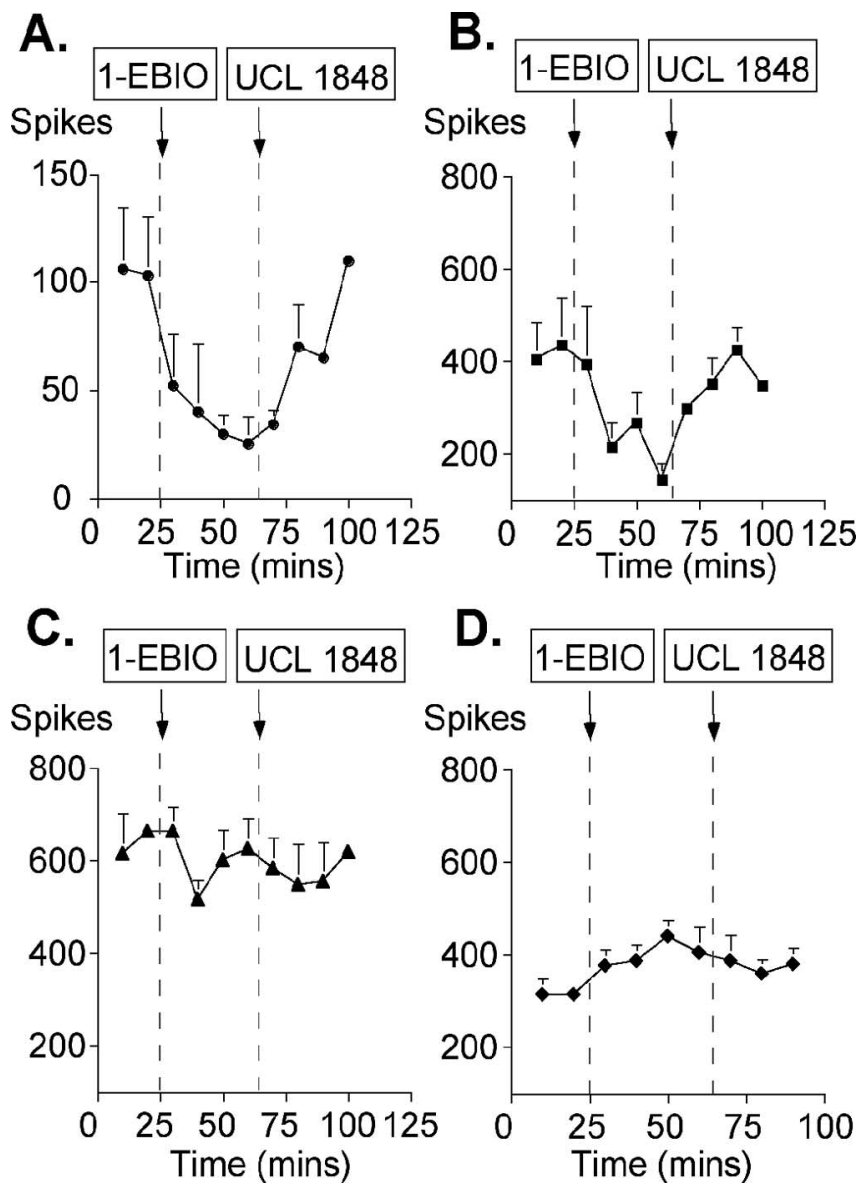

Figure 9. The effect of 1-EBIO, an enhancer of SK activity, on afferent fiber input in response to sensory stimuli. Stimulation using a von Frey $9 \mathrm{~g}$ fiber $(\boldsymbol{A})$, a von Frey $75 \mathrm{~g}$ fiber $(\boldsymbol{B})$, noxious heat $(\boldsymbol{C})$, and brush $(\boldsymbol{D})$ is shown. Each data point represents the response ( \pm SE) averaged from three recordings. Dashed lines indicate the point at which drugs were added (either $300 \mu \mathrm{m}$ 1-EBI0 or 10 nM U(L 1848).

sibility that drugs activating SK channels might have analgesic properties, as suggested also by our in vitro recording. To investigate this possibility, in a second series of studies, the effect of increasing SK channel activity was examined using 1-EBIO. UCL 1848 was applied subsequently in these experiments to test for reversal of the 1-EBIO effect. Here, we used natural stimuli to study the responses to these agents. In all three neurons tested, there were large reductions in responses evoked by von Frey $9 \mathrm{~g}$ and von Frey $75 \mathrm{~g}$ after the application of $300 \mu \mathrm{M}$ 1-EBIO (Fig. $9 A, B)$. These effects were rapidly and fully reversed by the subsequent application of $10 \mathrm{nM}$ UCL 1848. The observation of a dramatic change in the von Frey $75 \mathrm{~g}$ response appears to indicate that enhancing the activity of SK channels can produce substantial effects in pathways in which they are not normally dominant. [Similar examples, in which the activity of calcium-activated potassium channels is only prominent once it has been enhanced, have been reported in the CNS (Hu et al., 2001).] The effects of 1-EBIO on neuronal responses to heat were not pronounced compared with those seen using mechanical punctate stimuli and showed little reduction after treatment with the compound (Fig. 9C). The brush-evoked responses showed a modest facilitation (Fig. 9D). Our in vivo data confirm the findings in vitro; they demonstrate that SK channels play an important role in modulating sensory transmission and that by enhancing SK channel activity, it is possible to reduce substantially sensory afferent input.

\section{Discussion}

Calcium-activated potassium channels help to control neuronal excitability, and a number of reports suggest their involvement in nociceptive pathways. For example, in guinea pig and rabbit nodose afferents, calcium influx and calcium-induced calcium release activate potassium-selective channels that generate a slow postspike afterhyperpolarization. This AHP is abolished by inflammatory mediators, causing an increase in neuronal excitability and a reduction in spike frequency adaptation (Fowler et al., 1985; Cordoba-Rodriguez et al., 1999). Gold et al. (1996) reported a similarly slow, $\mathrm{Ca}^{2+}$-dependent afterhyperpolarization, regulated by prostaglandins, in cultured rat DRG neurons. Although these reports provide firm evidence for calcium-activated potassium conductances in sensory afferents, the relationship between these native channels and the cloned SK channels is not entirely clear. The nodose AHP channels are not blocked by apamin (Cordoba-Rodriguez et al., 1999), whereas a very high (1 $\mu \mathrm{M})$ concentration of apamin was used to block the slow AHP in rat neurons (Gold et al., 1996). Furthermore, many of the properties of these slow AHPs, such as their regulation and their slow kinetics, are similar to those of the slow afterhyperpolarizations found in hippocampal pyramidal neurons. Although the hippocampal AHP channels are potassium selective, have a small conductance, and require a calcium influx for activation, they appear to be unrelated to the cloned SK channels (Faber and Sah, 2003a; Vogalis et al., 2003; Bond et al., 2004; Villalobos et al., 2004). Thus, in sensory afferents, the relationship between the cloned SK channels and the conductances generating slow afterhyperpolarizations deserves additional investigation. However, channels that are blocked by low apamin concentrations and that produce AHPs lasting 100-500 ms (a duration more typically associated with AHPs attributed to the cloned SK channels), have also been reported in DRG neurons from a number of species. For example, Amir and Devor (1997) found apamin-sensitive afterhyperpolarizations when recording from rat A-type neurons, and Tokimasa et al. (1990) reported apamin-sensitive components of the AHPs in C-type neurons isolated from bullfrog DRGs. These findings are broadly consistent with our own observations, but SK-like channel activity appears infrequently in our recordings and this may go some way toward explaining the contradictory literature reports (Tokimasa et al., 1990; Amir and Devor, 1997; Abdulla and Smith, 2001).

Clearly, from the work discussed above, SK channels could help to control neuronal activity in both the large- and smalldiameter peripheral neurons in a number of species. However, the observation of some SK-mediated AHPs in DRG cell bodies leaves open several important questions, including the likely molecular identity of the channels involved, the potential role of SK channels in controlling sensory input into the spinal cord, and the potential therapeutic value of these channels. In the current study, we have shown that there are high levels of SK3 antibody staining in laminas I, II, and III of the dorsal horn of the spinal cord, which might be explained by SK3-like immunoreactivity present in both C-type and A-type DRG neurons. Recently, Sailer et al. (2004) provided good evidence of SK3 channel expression in the mouse spinal cord. Although they report their findings in slightly less detail, they observed SK3 immunoreactivity in the outer laminas of the dorsal horn and scattered SK3 staining in the ventral horn. Because Sailer et al. (2004) used a different antibody, raised to a different SK3 epitope, and because we were also able to confirm our SK3 staining with a commercially available SK3 antibody [Chemicon (Temecula, CA) antibody] (data not 
shown), we are confident that the SK3 immunoreactivity reflects expression of the SK3 protein. Interestingly, Sailer et al. (2004) also report low levels of SK2 immunoreactivity in the spinal cord of the mouse, which is again broadly consistent with our data in the rat. However, in contrast to our observations, they report high levels of SK1 immunoreactivity. The cause of this difference is not clear. It may be because of different affinities of the SK1 antibodies, but another possibility is that the differences arise because of alternative splicing in the SK1 gene. SK1 undergoes extensive alternative splicing, but only the longer SK1 isoforms appear to be capable of binding calmodulin and forming functional channels. The antibody we used for this study would only detect the longer isoforms, whereas Sailer and colleagues used antibodies that would detect all SK1 isoforms. Furthermore, Sailer et al. (2004) report that in the mouse brain, a short isoform of SK1 predominates, whereas in the rat brain, long and short isoforms of SK1 appear to be expressed fairly equally, so species differences could also be a contributing factor. From a functional point of view, SK1 is very unlikely to mediate the responses we see for two reasons. First, the rat SK1 protein appears to require SK2 subunits to form functional channels (Benton et al., 2003). Second, even if channels could be formed by SK1 via some unknown mechanism, in the absence of SK2, these are likely to be insensitive to most SK channel blockers (Benton et al., 2003; D'hoedt et al., 2004). For these reasons, SK3 appears to be the main SK channel mediating sensory responses, although we cannot rule out a contribution from SK2. The potential importance of these SK channels is illustrated by blocking their activity with UCL 1848 , a highly selective small molecule blocker with similar potency to apamin (Chen et al., 2000; Hosseini et al., 2001). Blocking SK channel activity substantially increases sensory input and demonstrates that SK channels are normally activated by the peripheral stimuli we used here.

Given our findings, it is interesting to note that an increasing body of literature points to a synaptic role for SK3 channels. For example, in hippocampal neurons, high-resolution immunofluorescent studies suggest that SK3 clusters on presynaptic glutamatergic (but not GABAergic) terminals (Obermair et al., 2003). Furthermore, antisense mRNA studies designed to knock down SK3 expression produce substantial increases in hippocampal long-term potentiation (Blank et al., 2003). Both of these CNS studies thus point to a role for SK3 channels in controlling transmitter release at presynaptic terminals. Furthermore, studies of the neuromuscular junction imply the same type of presynaptic role for SK3 there (Roncarati et al., 2001). In the light of this work, our (in vivo) recordings from lamina $\mathrm{V}$ wide dynamic range neurons raise the possibility that SK channels control sensory input into the spinal cord in a similar manner, but clearly, this would need to be established with additional experiments.

Our in vivo and in vitro results using 1-EBIO to enhance SK channel activity suggest a potentially valuable therapeutic use for SK channel modulation; by increasing SK channel activity, sensory input can be substantially reduced. As a result of the large effect of this compound on low- and high-intensity mechanical punctate stimuli, compounds related to 1-EBIO may be particularly useful in patients with mechanical allodynia/hyperalgesia accompanying persistent pain states (e.g., neuropathy). Interestingly, the compound (E)-2-(4,6-difluoro-1-indanylidene) acetamide is a potent analgesic and muscle relaxant with a similar structure to that of 1-EBIO (Musso et al., 2003a,b). This substance was reported recently to act as a novel enhancer of recombinant SK and IK channel activity, being considerably more potent than 1-EBIO [Cox B, Cryan JE, Dale TJ, Robertson GM,
Tresize DJ (2002) U.S. Patent Application PCT/GB02/00496, pending]. Similarly, some centrally acting drugs that may also have muscle relaxant and analgesic properties, such as chlorzoxazone, have also been shown to activate SK channels (Syme et al., 2000; Cao et al., 2001). Finally, behavioral studies using the drug resveratrol suggest that the peripheral antinociceptive effects of this compound can be blocked by apamin (Granados-Soto et al., 2002). Although much information about the physiological basis for the action of these drugs remains to be determined, their properties, in combination with the work here, suggest that compounds, selectively targeted toward particular SK channels, could prove to be useful in alleviating certain pain states, and therefore additional studies are needed to assess their clinical utility.

\section{References}

Abdulla FA, Smith PA (2001) Axotomy- and autotomy-induced changes in $\mathrm{Ca}^{2+}$ and $\mathrm{K}^{+}$channel currents of rat dorsal root ganglion neurons. J Neurophysiol 85:644-658.

Amir R, Devor M (1997) Spike-evoked suppression and burst patterning in dorsal root ganglion neurons of the rat. J Physiol (Lond) 501:183-196.

Banks BE, Brown C, Burgess GM, Burnstock G, Claret M, Cocks TM, Jenkinson DH (1979) Apamin blocks certain neurotransmitter-induced increases in potassium permeability. Nature 282:415-417.

Benton DCH, Monaghan AS, Hosseini R, Bahia PK, Haylett DG, Moss GWJ (2003) Small conductance $\mathrm{Ca}^{2+}$-activated $\mathrm{K}^{+}$channels formed by the expression of rat SK1 and SK2 genes in HEK 293 cells. J Physiol (Lond) 553:13-19.

Blank T, Nijholt I, Kye MJ, Radulovic J, Spiess J (2003) Small-conductance, $\mathrm{Ca}^{2+}$-activated $\mathrm{K}^{+}$channel SK3 generates age-related memory and LTP deficits. Nat Neurosci 6:911-912.

Blatz AL, Magleby KL (1986) Single apamin-blocked Ca-activated $\mathrm{K}^{+}$ channels of small conductance in cultured rat skeletal muscle. Nature 323:718-720.

Boettger MK, Till S, Chen MX, Anand U, Otto WR, Plumpton C, Trezise DJ, Tate SN, Bountra C, Coward K, Birch R, Anand P (2002) Calciumactivated potassium channel SK1- and IK1-like immunoreactivity in injured human sensory neurones and its regulation by neurotrophic factors. Brain 125:252-263.

Bond CT, Herson PS, Strassmaier T, Hammond R, Stackman R, Maylie J, Adelman JP (2004) Small conductance $\mathrm{Ca}^{2+}$-activated $\mathrm{K}^{+}$channel knock-out mice reveal the identity of calcium-dependent afterhyperpolarization currents. J Neurosci 24:5301-5306.

Cao Y, Dreixler JC, Roizen JD, Roberts MT, Houamed KM (2001) Modulation of recombinant small-conductance $\mathrm{Ca}^{2+}$-activated $\mathrm{K}^{+}$channels by the muscle relaxant chlorzoxazone and structurally related compounds. J Pharmacol Exp Ther 296:683-689.

Chen JQ, Galanakis D, Ganellin CR, Dunn PM, Jenkinson DH (2000) bisQuinolinium cyclophanes: 8,14-diaza-1,7(1, 4)-diquinolinacyclotetradecaphane (UCL 1848), a highly potent and selective, nonpeptidic blocker of the apamin-sensitive $\mathrm{Ca}^{2+}$-activated $\mathrm{K}^{+}$channel. J Med Chem 43:3478-3481.

Cingolani LA, Gymnopoulos M, Boccaccio A, Stocker M, Pedarzani P (2002) Developmental regulation of small-conductance $\mathrm{Ca}^{2+}$-activated $\mathrm{K}^{+}$ channel expression and function in rat Purkinje neurons. J Neurosci 22:4456-4467.

Colquhoun D (1971) Lectures on biostatistics, Chaps 6, 8. London: Oxford UP.

Cordoba-Rodriguez R, Moore KA, Kao JP, Weinreich D (1999) Calcium regulation of a slow post-spike hyperpolarization in vagal afferent neurons. Proc Natl Acad Sci USA 96:7650-7657.

Devor DC, Singh AK, Frizzell RA, Bridges RJ (1996) Modulation of $\mathrm{Cl}^{-}$ secretion by benzimidazolones. I. Direct activation of $\mathrm{C} \mathrm{Ca}^{2+}$-dependent $\mathrm{K}^{+}$channel. Am J Physiol 271:L775-L784.

D'hoedt D, Hirzel K, Pedarzani P, Stocker M (2004) Domain analysis of the calcium-activated potassium channel SK1 from rat brain. Functional expression and toxin sensitivity. J Biol Chem 279:12088-12092.

Faber ES, Sah P (2003a) Calcium-activated potassium channels: multiple contributions to neuronal function. The Neuroscientist 9:181-194.

Faber ES, Sah P (2003b) $\mathrm{Ca}^{2+}$-activated $\mathrm{K}^{+}$(BK) channel inactivation contributes to spike broadening during repetitive firing in the rat lateral amygdala. J Physiol (Lond) 552:483-497. 
Fowler JC, Greene R, Weinreich D (1985) Two calcium-sensitive spike after-hyperpolarizations in visceral sensory neurones of the rabbit. J Physiol (Lond) 365:59-75.

Furness JB, Robbins HL, Selmer IS, Hunne B, Chen MX, Hicks GA, Moore S, Neylon CB (2003) Expression of intermediate conductance potassium channel immunoreactivity in neurons and epithelial cells of the rat gastrointestinal tract. Cell Tissue Res 314:179-189.

Gold MS, Shuster MJ, Levine JD (1996) Role of a $\mathrm{Ca}^{2+}$-dependent slow afterhyperpolarization in prostaglandin E2-induced sensitization of cultured rat sensory neurons. Neurosci Lett 205:161-164.

Goldstein ME, House SB, Gainer H (1991) NF-L and peripherin immunoreactivities define distinct classes of rat sensory ganglion cells. J Neurosci Res 30:92-104.

Granados-Soto V, Arguelles CF, Ortiz MI (2002) The peripheral antinociceptive effect of resveratrol is associated with activation of potassium channels. Neuropharmacology 43:917-923.

Greffrath W, Martin E, Reuss S, Boehmer G (1998) Components of afterhyperpolarization in magnocellular neurones of the rat supraoptic nucleus in vitro. J Physiol (Lond) 513:493-506.

Guo A, Vulchanova L, Wang J, Li X, Elde R (1999) Immunocytochemical localization of the vanilloid receptor 1 (VR1): relationship to neuropeptides, the P2X3 purinoceptor and IB4 binding sites. Eur J Neurosci 11:946-958.

Hosseini R, Benton DCH, Dunn PM, Jenkinson DH, Moss GWJ (2001) SK3 is an important component of $\mathrm{K}^{+}$channels mediating the afterhyperpolarization in cultured rat SCG neurones. J Physiol (Lond) 535:323-334.

Hounsgaard J, Kiehn O, Mintz I (1988) Response properties of motoneurones in a slice preparation of the turtle spinal cord. J Physiol (Lond) 398:575-589.

Hu H, Shao LR, Chavoshy S, Gu N, Trieb M, Behrens R, Laake P, Pongs O, Knaus HG, Ottersen OP, Storm JF (2001) Presynaptic $\mathrm{Ca}^{2+}$-activated $\mathrm{K}^{+}$channels in glutamatergic hippocampal terminals and their role in spike repolarization and regulation of transmitter release. J Neurosci 21:9585-9597.

Kohler M, Hirschberg B, Bond CT, Kinzie JM, Marrion NV, Maylie J, Adelman JP (1996) Small-conductance, calcium-activated potassium channels from mammalian brain. Science 273:1709-1714.

Lüscher C, Streit J, Lipp P, Lüscher HR (1994) Action potential propagation through embryonic dorsal root ganglion cells in culture. II. Decrease of conduction reliability during repetitive stimulation. J Neurophysiol 72:634-643.

MacVinish LJ, Hickman ME, Mufti DA, Durrington HJ, Cuthbert AW (1998) Importance of basolateral $\mathrm{K}^{+}$conductance in maintaining $\mathrm{Cl}^{-}$ secretion in murine nasal and colonic epithelia. J Physiol (Lond) 510:237-247.

Monaghan AS, Benton DCH, Bahia PK, Hosseini R, Shah YA, Haylett DG, Moss GWJ (2004) The SK3 subunit of small conductance $\mathrm{Ca}^{2+}$. activated $\mathrm{K}^{+}$channels interacts with both SK1 and SK2 subunits in a heterologous expression system. J Biol Chem 279:1003-1009.

Musso DL, Cochran FR, Kelley JL, McLean EW, Selph JL, Rigdon GC, Orr GF, Davis RG, Cooper BR, Styles VL, Thompson JB, Hall WR (2003a) Indanylidenes. 1. Design and synthesis of (E)-2-(4,6-difluoro-1indanylidene)acetamide, a potent, centrally acting muscle relaxant with antiinflammatory and analgesic activity. J Med Chem 46:399-408.

Musso DL, Orr GF, Cochran FR, Kelley JL, Selph JL, Rigdon GC, Cooper BR, Jones ML (2003b) Indanylidenes. 2. Design and synthesis of (E)-2-(4- chloro-6-fluoro-1-indanylidene)- $N$-methylacetamide, a potent antiinflammatory and analgesic agent without centrally acting muscle relaxant activity. J Med Chem 46:409-416.

Obermair GJ, Kaufmann WA, Knaus HG, Flucher BE (2003) The small conductance $\mathrm{Ca}^{2+}$-activated $\mathrm{K}^{+}$channel SK3 is localized in nerve terminals of excitatory synapses of cultured mouse hippocampal neurons. Eur J Neurosci 17:721-731.

Oblinger MM, Wong J, Parysek LM (1989) Axotomy-induced changes in the expression of a type III neuronal intermediate filament gene. J Neurosci 9:3766-3775.

Otsuka M, Konishi S (1974) Electrophysiology of mammalian spinal cord in vitro. Nature 252:733-734.

Pedarzani P, Mosbacher J, Rivard A, Cingolani LA, Oliver D, Stocker M, Adelman JP, Fakler B (2001) Control of electrical activity in central neurons by modulating the gating of small conductance $\mathrm{Ca}^{2+}$-activated $\mathrm{K}^{+}$ channels. J Biol Chem 276:9762-9769.

Rhodes JD, Collison DJ, Duncan G (2003) Calcium activates SK channels in the intact human lens. Invest Ophthalmol Vis Sci 44:3927-3932.

Roncarati R, Di Chio M, Sava A, Terstappen GC, Fumagalli G (2001) Presynaptic localization of the small conductance calcium-activated potassium channel SK3 at the neuromuscular junction. Neuroscience 104:253-262.

Sailer CA, Kaufmann WA, Marksteiner J, Knaus HG (2004) Comparative immunohistochemical distribution of three small-conductance $\mathrm{Ca}^{2+}$ activated potassium channel subunits, SK1, SK2, and SK3 in mouse brain. Mol Cell Neurosci 26:458-469.

Stocker M, Pedarzani P (2000) Differential distribution of three $\mathrm{Ca}^{2+}$. activated $\mathrm{K}^{+}$channel subunits, SK1, SK2, and SK3, in the adult rat central nervous system. Mol Cell Neurosci 15:476-493.

Syme CA, Gerlach AC, Singh AK, Devor DC (2000) Pharmacological activation of cloned intermediate- and small-conductance $\mathrm{Ca}^{2+}$-activated $\mathrm{K}^{+}$channels. Am J Physiol Cell Physiol 278:C570-C581.

Thompson SW, Gerber G, Sivilotti LG, WoolfCJ (1992) Long duration ventral root potentials in the neonatal rat spinal cord in vitro; the effects of ionotropic and metabotropic excitatory amino acid receptor antagonists. Brain Res 595:87-97.

Tokimasa T, Shiraishi M, Akasu T (1990) Morphological and electrophysiological properties of C-cells in bullfrog dorsal root ganglia. Neurosci Lett 116:304-308

Tominaga M, Caterina MJ, Malmberg AB, Rosen TA, Gilbert H, Skinner K, Raumann BE, Basbaum AI, Julius D (1998) The cloned capsaicin receptor integrates multiple pain-producing stimuli. Neuron 21:531-543.

Urch CE, Dickenson AH (2003) In vivo single unit extracellular recordings from spinal cord neurones of rats. Brain Res Brain Res Protoc 12:26-34.

Villalobos C, Shakkottai VG, Chandy KG, Michelhaugh SK, Andrade R (2004) SKCa channels mediate the medium but not the slow calciumactivated afterhyperpolarization in cortical neurons. J Neurosci 24:3537-3542.

Villiere V, McLachlan EM (1996) Electrophysiological properties of neurons in intact rat dorsal root ganglia classified by conduction velocity and action potential duration. J Neurophysiol 76:1924-1941.

Vogalis F, Storm JF, Lancaster B (2003) SK channels and the varieties of slow after-hyperpolarizations in neurons. Eur J Neurosci 18:3155-3166.

Zhang L, Krnjevic K (1987) Apamin depresses selectively the afterhyperpolarization of cat spinal motoneurons. Neurosci Lett 74:58-62. 